\title{
Mapas mentais de deficientes visuais como suporte ao design da informação urbana na Web
}

\author{
Mind maps by the visually impaired as a support to the urban information design on \\ the Web
}

\author{
Geisa Golin, Ruth E. Nogueira, Gabriela C. Alexandre e Josiane M. Cabral
}

deficiente visual, mapas mentais, Web

\begin{abstract}
Reconhecer a pessoa com deficiência visual é, estranhamente, romper preconceitos e se aproximar de uma realidade ao mesmo tempo corriqueira. Adaptar a cidade aos diferentes usuários que nela habitam é um direito prescrito em lei e, portanto hoje é imprescindível considerar a acessibilidade urbana como forte designador de projetos urbanos. Este artigo visa entender a cidade dos deficientes visuais, seus mapas mentais de rotas urbanas e a disponibilização destas informações geradas pelas pessoas com deficiência visual na Web, ou seja, levar a outros cidadãos informações sobre a cidade de Florianópolis, porém analisadas e verificadas por e para deficientes visuais. Considerar os padrões Web de acessibilidade são foco deste artigo, porém além destes, é fundamental reconhecer o usuário que deles fará uso. A simples transcrição de informações de um sítio Web comum para um sítio Web acessível pode não ser tão eficaz se considerarmos a forma como os conceitos são formados e verificados por este grupo de usuários.
\end{abstract}

visually impaired,, mind maps, Web

To recognize the visually impaired is, interestingly, to break prejudices and get in touch with a reality that is at the same time quite common. The adaptation of the city to the different users that live in it is a right that is guaranteed by law, so nowadays it is crucial to consider urban accessibility as a strong parameter for urban projects. This article intends to understand the visually impaired's city, its mental maps for the urban routes and the availability of this information generated by the visually impaired on the web; in other words, to bring information about the city of Florianópolis to other citizens, analyzed and verified by and for the visually impaired. The focus of this article is to consider the web accessibility standards, but not only those, it is also very important to recognize the user that is going to access them. The simple transcription of information from a regular website to an accessible website can be ineffective if we consider the way the concepts are developed and verified by this group of users.

\section{Introdução}

Há muito tempo pessoas ditas "cegas" não são mais confundidas com mendigos, ou como sendo doentes; elas fazem parte da cidade, ao menos da nossa. Elas participam da vida urbana, produzindo e desfrutando da vida social nos seus diferentes aspectos: andando pelas ruas, estudando em escolas regulares, trabalhando e pagando as suas contas. E, a não ser pela bengala, em muitos momentos em nada percebemos a sua cegueira física. Esse, talvez seja um "ponto de vista" de alguém próximo ao universo de quem não enxerga. Contudo, a população em geral sabe que a abordagem com relação às minorias, assim como as (d)eficiências humanas estão mudando dia-a-dia, seja por força de lei, seja por que o homem da era da informação e do mundo globalizado precisa sentir-se humanizado. Tal mudança vem acontecendo de forma lenta e gradativa, mas firme.

Não há como entender as necessidades de um grupo de minoria sem escutá-los, sem de fato reconhecer que eles são cidadãos com deveres e direitos. Então, das muitas formas de conhecer quais são as reais necessidades dessas minorias no meio urbano, optamos por investigar alguns deficientes visuais (tratados doravante como invisuais), questionando-o sobre sua relação com o espaço onde vive. Obtendo o entendimento de como se dá a mobilidade destes cidadãos no meio urbano, se poderá de alguma maneira, auxiliá-los nesse afã, e quem sabe mostrar outros aspectos do espaço urbano que eles desconhecem.

Acredita-se que representações gráficas táteis e sonoras poderiam ser muito úteis como meio de informação de "como sair daqui e chegar lá". Foi com essa crença que desenvolveu-se um projeto com deficientes visuais que circulam pelo centro de Florianópolis. Primeiro foram investigados junto a eles quais os referenciais que utilizam para se 


\section{Infodesıgn}

locomoverem na cidade, $\mathrm{e}$

como criam mapas mentais de rotas urbanas específicas, ouvindo seus relatos e analisando seus desenhos ilustrativos. Com esse conhecimento, foram propostas a eles alternativas gráficas sonoras para representar tais rotas, considerando que, uma vez compreendidos por eles, esses mapas táteis de rotas poderiam servir para ajudar outros deficientes visuais a aprenderem esses caminhos.

O trabalho desenvolvido com um grupo de cinco voluntários da Associação Catarinense para a Integração do Cego será relatado nesse texto na parte que trata da investigação de o que é a cidade para eles, como constroem seus mapas mentais de rotas urbanas, até chegarmos às representações gráficas e sonoras. Uma segunda parte do trabalho desenvolvido diz respeito a colocar essas e outras informações urbanas na Internet (no endereço (www.floripacessivel.com) para que qualquer usuário invisual possa ter acesso a ela, e quem sabe, locomover-se com mais autonomia na cidade.

\section{Cidade e Mobilidade}

Sempre que se pensa no contexto de cidade é comum ter em mente um grande amontoado de casas, pessoas, animais domésticos, automóveis. Se fosse possível dar um zoom nesta imagem recriada em mente, nosso pensamento seria detalhado, e a partir de casas, pessoas, automóveis, seria possível observar ruas, estradas, grandes avenidas; para em seguida, escutarmos os ruídos desta cidade. Ruídos graves, ruídos agudos, ruídos ensurdecedores, ruídos produzidos por máquinas e uma imensidão de seres que convivem em sociedade.

As imagens e representações que cada um de nós faz da cidade em que vive leva consigo toda a experiência vivida neste espaço. São percepções, análises, significações e lembranças do repertório cotidiano. São ainda mais, são alicerces para viver e progredir em comunidade.

Esta primeira imagem aglomerada de habitações, seres, movimento e vida em desenvolvimento pode significar cidade, porém de forma muito genérica, e muito global. $\mathrm{O}$ detalhamento desta reflexão de cidade, entretanto, faz com que a homogeneidade de uma grande massa seja diluída em partes, para dar espaço à história de cada pedaço desta cidade, de cada ser humano que dela faz parte, de cada espaço de terra, que ali está por uma razão específica de ser.

Dentre um grupo de serviços públicos que devem ser oferecidos pelo poder público na cidade está o que chamamos de mobilidade. Mobilidade urbana é ter acesso aos diferentes lugares de uma cidade. De nada adianta construir um grande parque público se o governo não disponibiliza vias de acesso a este espaço, ou então transporte público que viabilize aos cidadãos chegar neste parque.

Mobilidade, segundo Scaringella, 2001, é um desafio tecnológico, político e administrativo que exige um tratamento mais holístico e menos setorizado e um amplo debate com todos os segmentos representativos. (SCARINGELLA, 2001)

'Uma boa acupuntura é permitir que o som natural das cidades possa ser ouvido. Fazer silêncio para depurar o verdadeiro som. Afinar o som da cidade.' (LERNER, 2005:144) Sábias palavras de Jaime Lerner que evidenciam a cura da cidade, o seu planejamento e o seu repaginamento.

Mobilidade é simples de ser explicada e difícil de ser concebida. Talvez porque as pessoas que dela farão uso tenham particularidades distintas, e necessidades diversas. Para um deficiente visual, por exemplo, não basta apenas pensar no transporte público de qualidade, é preciso ter consciência para cuidar das calçadas por onde circula a multidão. De nada adianta colocar pisos guias em uma parte da cidade, se as calçadas são esburacadas. Melhor seria se as calçadas comuns estivessem bem cuidadas. 
A atenção com a instalação de rampas, placas de trânsito e janelas que não abram para fora, em meio às calçadas, são extremamente importantes para a mobilidade dos invisuais (não videntes). Em muitas situações o recuo de alguns centímetros de uma placa de trânsito evitaria um obstáculo perigoso na mobilidade destas pessoas.

As faixas para pedestres também significam dificuldade para quem não enxerga, isto porque estas são representadas apenas por sinais visuais. Em muitos países europeus elas não são mais um problema, pois um sinal sonoro instalado em frente às faixas indica o momento em que a pessoa pode fazer a travessia. Um tipo de freqüência sonora informa que não se deve atravessar e uma segunda freqüência de som indica que é possível atravessar.

Segundo Acselrad, 2001, as decisões sobre a organização do espaço e da vida social e cultural ultrapassam a problemática e a competência tecnico-instrumental dos planejadores e tecnocratas, configurando uma situação que exige o diálogo, a comunicação e a interação consciente de toda a comunidade." (ACSELRAD, 2001)

\section{O usuário deficiente visual}

Normalmente ao se deparar com pessoas com deficiência visual é possível ter intrinsecamente um olhar muitas vezes angustiado ou aflito, advindo de um contexto histórico inerente à nossa sociedade. É comum, neste momento ficar triste ou pensativo por um instante. Talvez devido ao fato de que por muito tempo eles foram considerados habitantes de um mundo de trevas e de escuridão; eram pessoas renegadas perante a sociedade, quase não saiam de suas casas sozinhos, e suas famílias, na maioria, pouco entendiam as suas necessidades.

O Instituto Laramara (2007) diz que a pessoa com deficiência visual pode ser cega ou ter baixa visão. $O$ indivíduo cego não enxerga. $O$ indivíduo com baixa visão enxerga pouco, mesmo após tratamento ou uso de óculos comuns. Cada pessoa com baixa visão terá uma maneira diferente de ver o ambiente, os objetos e as pessoas. Por isto é tão difícil encontrar estudos envolvendo usuários baixa visão. Segundo dados do IBGE, existe um universo de 16,5 milhões de deficientes visuais no Brasil. (IBGE, 2000)

A deficiência visual interfere em habilidades e capacidades e afeta, não somente a vida da pessoa que perdeu a visão, mas também dos membros da família, amigos, colegas, professores, empregadores e outros. Entretanto, com tratamento precoce, atendimento educacional adequado, programas e serviços especializados, a perda da visão não significará o fim da vida independente e não ameaçará a vida plena e produtiva. (IBC, 2007).

\section{Mapas mentais de deficientes visuais}

O reconhecimento do lugar onde se vive influencia diante dos atos de cada cidadão, das suas ambições, do seu comportamento. É o espaço do qual se faz uso que condiciona os desejos e as intenções de todos. Se um indivíduo habita em uma cidade com muitas praias, parques ou serviços culturais, é inevitável que, como cidadão desta cidade, como parte dela, queira estar nestes lugares, mesmo que poucas vezes durante a semana.

Os lugares por onde se passa, as ruas pelas quais se anda, o caminho que se faz todos os dias até o trabalho, ou a estrada percorrida no final de semana, são os referenciais que cada um possui na "sua cidade". Tais referências são acumuladas em nossa mente e guardadas para que se tenha uma solução quando se necessitar de uma indicação, de um nome de rua, de uma referência de caminho mais rápido e viável, ou apenas para se reconhecer um lugar e demarcar o espaço vivido.

A forma como se organizam os pensamentos e as informações está ligada à experiência concebida em determinado lugar. Mesmo que não se pense nesta organização, de 
alguma forma ela existe e pode ser investigada. Uma das maneiras de se estudar a organização espacial de cada um de nós, se dá por meio de mapas mentais.

Mapas mentais são gráficos de categorias, onde é possível eleger e hierarquizar conceitos de um determinado indivíduo sobre um assunto em questão. Os conceitos são chamados de [nós], e são interligados por relações, que são as [arestas]. Os mapas mentais são construídos individualmente e têm como objetivo auxiliar ou à pessoa que o fez, ou então a algum pesquisador que tenha necessidade de conhecer as informações organizadas sobre tal usuário.

$\mathrm{Na}$ geografia os mapas mentais estão relacionados às características percebidas pelo sujeito no mundo real, por intermédio de processos oriundos da percepção, das lembranças do consciente e do inconsciente, assim como do contexto sociocultural a que o indivíduo pertence (KOZEL, 2006).

Cremonini (1998) afiança que os mapas mentais na Geografia são caracterizados pela obtenção de informações verbais e gráficas. Para tanto o pesquisador solicita que o usuário de um determinado local desenhe esse espaço, associando esses dados àqueles adquiridos através de entrevistas ou mesmo de conversas informais.

Ao aplicar a técnica dos mapas mentais para usuários videntes e não videntes é possível analisar e entender diferenças notáveis quanto à disposição de obstáculos urbanísticos e rotas urbanas que teoricamente são projetadas para todos.

No mapa mental de um não vidente, por exemplo, é comum, ao relatar uma rota urbana, enfatizar a disposição de orelhões pelas ruas. Este fato se dá não porque os orelhões sejam importantes para os deficientes visuais, mas porque são barreiras urbanas que ameaçam sua integridade física durante sua mobilidade. Por isso ao invés do usuário relatar como referência de rota a padaria da esquina, é muito comum que ele relate o orelhão da esquina.

O mapa mental de uma pessoa com deficiência visual sobre uma rota urbana pode ser concebido de forma gráfica e tátil, conservando os níveis hierárquicos relatados para as informações [lugares] mais importantes, como veremos mais adiante.

\section{Desvendando a cidade das pessoas com deficiência visual}

A cidade relatada nesta experiência é a capital do estado de Santa Catarina: Florianópolis. Uma cidade com muitas características incomuns, uma ilha circundada por 42 praias e 2 lagoas ao seu interno, o relevo composto por um maciço central, com configuração descontínua de vários morros e a linha de costa composta pelas restingas e praias, proporciona o contato com a natureza. As áreas habitáveis se concentram no centro da ilha, na parte continental, na parte leste, norte e sul. Cada uma delas possui características específicas quanto à geografia, urbanização e mobilidade.

O centro Urbano e histórico da cidade destaca-se por apresentar edificações com significativo valor histórico preservado. Mantém uma concentração de atividades comerciais e de serviços.

A economia da cidade gira em torno principalmente das atividades pesqueiras, do turismo, das atividades do funcionalismo público e mais recentemente com o surgimento das empresas de tecnologia.

\section{Metodologia de investigação}

O grupo de pessoas que participou voluntariamente desta experiência foi composto por uma orientadora de mestrado, uma mestranda, dois acadêmicos do curso de geografia e cinco colaboradores da Associação Catarinense para a Integração do Cego - ACIC, 
considerada a maior associação do sul do país, referência no ensino a cegos.

Os colaboradores deficientes visuais fazem parte de uma faixa etária de 25 a 43 anos, sendo apenas um do sexo feminino. O grau de instrução do grupo é alto, todos eles terminaram o ensino médio e trabalham. Dois possuem graduação e pós-graduação. Dentre os participantes um deles possui cegueira congênita, um cegou aos 7 anos, outro aos 18 anos, outro aos 35 anos e o último possui baixa-visão.

As reuniões programadas foram estendidas a dez encontros, sendo o penúltimo uma saída de campo individual com cada um dos participantes e o último uma análise da rota urbana criada pelo grupo.

O método empregado junto ao grupo foi, primeiramente, não transparecer que ali se fazia uma pesquisa científica. Para tanto se abordou o discurso de equipe e não de grupo de pesquisa. Esta equipe estava consciente de que juntos se investigariam as informações com o objetivo de disponibilizar um sítio na Web com informações da cidade. Para tanto era necessário esclarecer o que era a cidade de Florianópolis e quais serviços seriam importantes serem informados via internet para os deficientes visuais.

As reuniões aconteceram em uma sala de aula da instituição em portas fechadas, sob a mediação da mestranda. As perguntas e indagações foram feitas, algumas vezes de forma frontal a algum dos participantes, e algumas vezes de forma geral a todos. Cada reunião foi documentada em uma ficha previamente preparada, com os assuntos pertinentes àquela reunião para cada participante. Conforme os assuntos eram abordados, a equipe de pesquisadores tomava nota dos dados fornecidos, bem como de expressões verbais, trejeitos, pensamentos e idéias de cada um deles.

Os assuntos tratados inicialmente foram: a cidade de Florianópolis, os serviços públicos e os serviços públicos referenciados por eles. Tais assuntos foram tratados primeiro de forma genérica e depois específica, isto é, abrangiam a cidade como um todo até chegar às particularidades da cidade. Indagamos o que seria um serviço público, quais os serviços públicos mais conhecidos e utilizados por cada participante dessa equipe.

$\mathrm{Na}$ antepenúltima reunião do grupo, cada participante, individualmente, relatou um serviço público previamente escolhido pelos pesquisadores, de forma verbal.

Surpreendentemente cada um dos participantes deficientes visuais fez diferentes objeções quanto ao Terminal Rodoviário Rita Maria em Florianópolis. Todos eles abordaram rotas diferentes para se acessar o lugar, e todos eles deram descrições diferenciadas para este serviço público.

Um dos participantes disse: "[...] ir à rodoviária significa um desafio para mim". Alguns contaram não conhecer a região, como um todo, conhecendo, porém, apenas os pontos por onde passavam, por onde a bengala tocava, ou por onde precisavam cruzar por alguma necessidade do dia. "Eu vou só até a rodoviária, que já é bastante coisa", disse um dos entrevistados. Um dos participantes disse ir até a loja de doces que encontra-se dentro da rodoviária, e quando ficou sabendo que ali dentro havia uma lotérica lastimou não saber antes esta informação, pois "ali seria possível pagar algumas contas", disse. Todos eles disseram que no dia em que vão à rodoviária é um dia único, e que não aproveitam este momento para utilizar/passar em nenhum serviço dos arredores. Um dos participantes avisa: "banheiros são difíceis de usar" e outro, ao ser perguntado sobre a sensação de estar dentro da rodoviária respondeu: "Sinto felicidade por conseguir chegar e achar o que queria."

A próxima reunião do grupo foi individual, cada participante deficiente visual percorreu junto aos pesquisadores a rota urbana desenvolvida por ele para se chegar à rodoviária. Neste caminho foram observadas diferentes estratégias de acesso ao lugar e apontamentos importantes sobre a mobilidade de cada um deles. 


\section{Infodesıgn}

Figura 1 - Participante deficiente visual percorrendo o centro de Florianópolis.

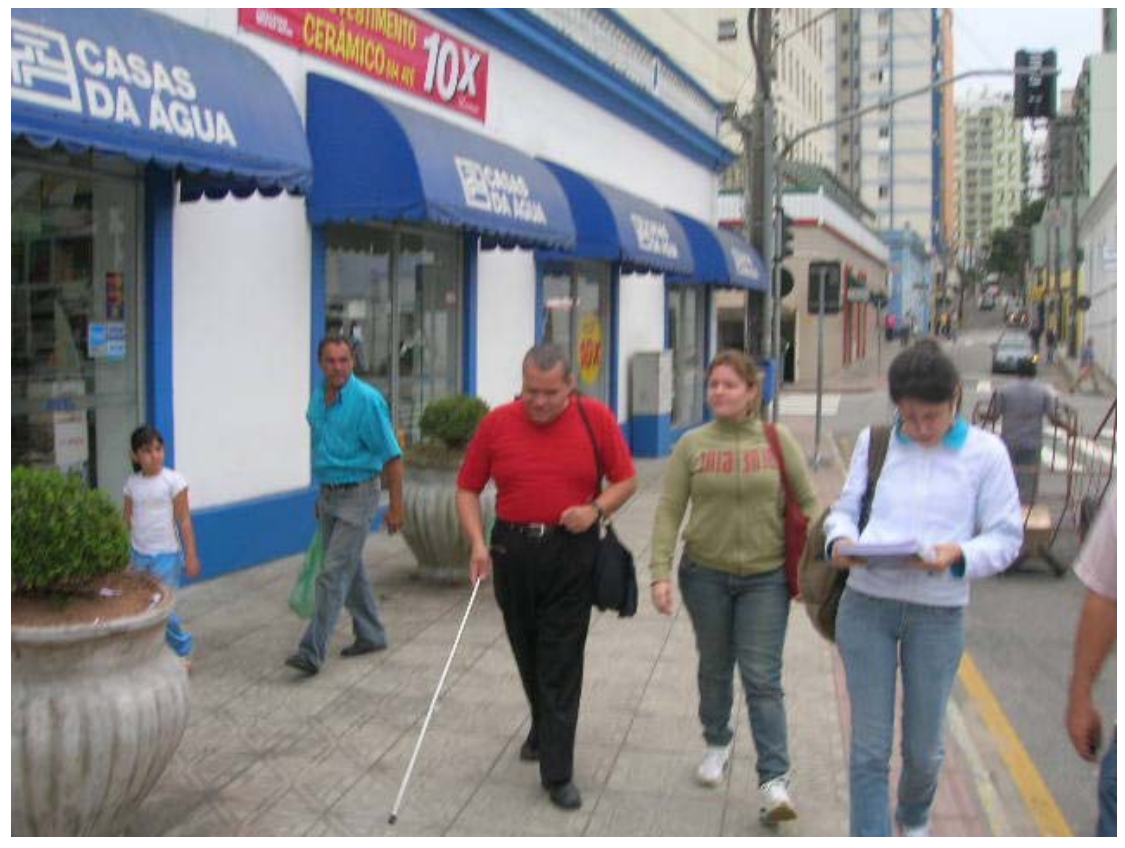

Na reunião seguinte, que seria a penúltima reunião do grupo, os participantes foram abordados com materiais táteis desenhos (papel, pasta em relevo e giz de cera), para que representassem o caminho, por eles já percorrido, até a rodoviária. Este mecanismo de observação foi repudiado por um dos participantes invisuais que disse estar inibido e inseguro, visto que muito pouco foi estimulado a desenhar. Os pesquisadores alertaram que a qualidade gráfica do desenho não seria importante na avaliação, mas sim os pontos localizados na rota urbana desenhada. Acreditou-se ser esta uma avaliação importante para dar credibilidade aos dados anteriormente coletados, visto que em outras oportunidades os participantes já teriam relatado a rodoviária de forma verbal e que já teriam acessado este serviço público com os pesquisadores.

Figura 2 - Representação da rota terminal urbano até a rodoviária feita por um dos participantes invisuais - os texto das caixas são as explicações verbalizadas pela pessoa que desenhou.

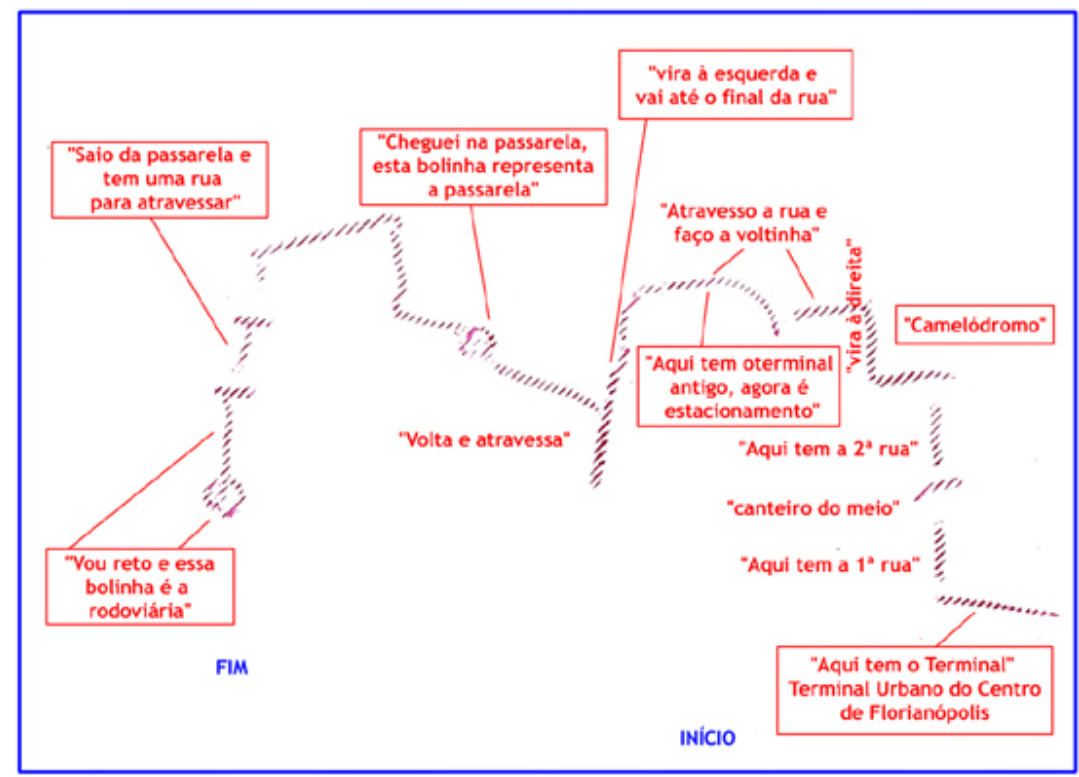


Na última reunião do grupo os pesquisadores levaram um mapa tátil da rota urbana de chegada à rodoviária, elaborado segundo as informações relevantes descritas pelos cinco participantes invisuais da pesquisa. O percurso eleito pela equipe foi o mais seguro e com melhor infraestrutura abordado nas reuniões.

Os participantes invisuais ao se depararem com o mapa tátil de rotas foram induzidos a compreender todas as informações táteis disponíveis. Os pesquisadores obtiveram sucesso ao perceber que todos os participantes invisuais tinham compreendido a rota explicitada no mapa, bem como puderem incrementar tais informações com outros apontamentos.

Figura 3 - Mapa tátil da rota terminal urbano até a rodoviária elaborado pelos pesquisadores - os textos em negrito servem apenas para o entendimento visual.

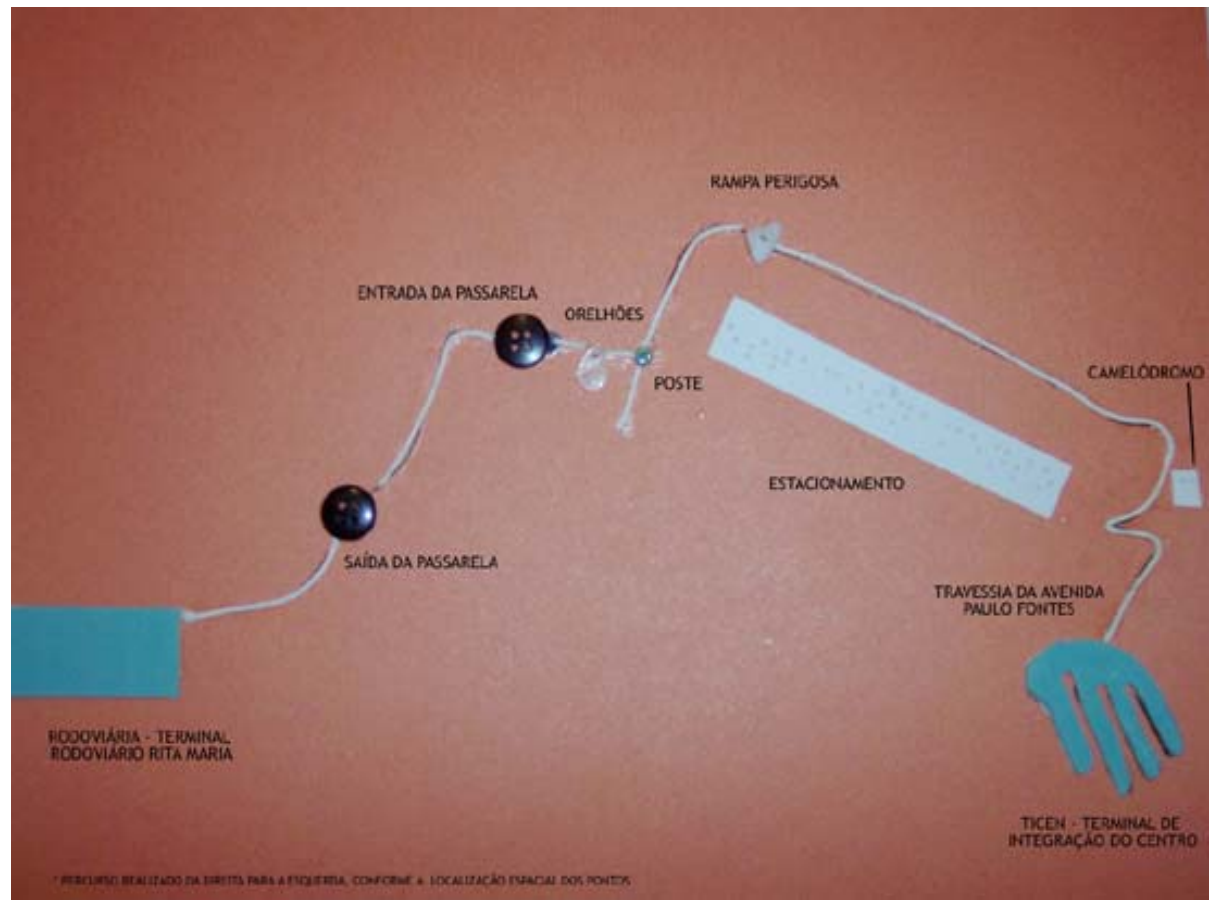

\section{A Web como facilitadora do acesso à cidade}

Complementando a pesquisa de campo realizada junto à ACIC a dissertação de mestrado envolveria ainda a disponibilização de rotas e mapas de uma forma abrangente, e que desse ao usuário deficiente visual autonomia ao acesso.

Para tanto o meio encontrado para disponibilizar estas informações foi a Web, grande rede de computadores interligados. O contingente informacional que está disponível na Rede aumenta e se modifica constantemente, onde a análise dos usuários que dela fazem uso é outro ponto fundamental para que os projetistas e desenvolvedores Web obtenham sucesso. Por outro lado, considerar o deficiente visual como usuário da Web requer normativas especiais, as quais fazem com que a acessibilidade seja assegurada para eles.

Algumas iniciativas como o World Wide Web Consortium, ou apenas W3C, a sigla mundialmente reconhecida como promotora de padrões para criação e disponibilização de informação para a Web, propiciam a sua acessibilidade. Trata-se de um consórcio de empresas tecnológicas, com mais de 400 membros, que tem como lema "conduzir a Web ao seu potencial máximo", visando o desenvolvimento de ferramentas, padrões e possibilidades para a interpretação de conteúdos na Web. (W3C, 2007) 


\section{Infodesıgn}

Outra iniciativa de renome, é a Web Acessibility Initiative (WAI), que faz parte do W3C, mas que promove iniciativas de disponibilização não apenas de novos conteúdos, visando à acessibilidade, mas também organiza fóruns internacionais entre indústria, organizações de deficientes, pesquisadores de acessibilidade, governo e demais interessados em acessibilidade na Web. (WAI, 2007)

O Web Design Group, outro grupo promotor da acessibilidade, foi fundado com o objetivo de instigar a criação de sites acessíveis, sem especificar browsers ou resoluções específicas de uso. Com esta finalidade, o WDG oferece diversos tipos de materiais destinados ao uso da linguagem HTML. (WDG, 2007).

Seguindo os padrões Web ou as "Web Standards" esta pesquisa visou o projeto de um sistema Web acessível para deficientes visuais com informações relevantes para este público. Nascera o FloripAcessível.com, um sítio de informações cadastrais da cidade de Florianópolis desenvolvido e administrado por e para usuários da Web deficientes visuais.

Segundo os dados W3C (Consórcio para a WEB) e WAI (Iniciativa para a Acessibilidade na Rede) algumas situações e características dos usuários são apontadas como imprescindíveis no projeto de um Web site:

- Incapacidade de ver, ouvir ou deslocar-se, ou grande dificuldade - quando não a impossibilidade - de interpretar certos tipos de informação.

- Dificuldade visual para ler ou compreender textos.

- Incapacidade para usar o teclado ou o mouse, ou não dispor deles.

- Insuficiência de quadros, apresentando apenas texto ou dimensões reduzidas, ou uma ligação muito lenta à Internet.

- Dificuldade para falar ou compreender, fluentemente, a língua em que o documento foi escrito.

- Ocupação dos olhos, ouvidos ou mãos, por exemplo, ao volante a caminho do emprego, ou no trabalho em ambiente barulhento.

- Desatualização, pelo uso de navegador com versão muito antiga, ou navegador completamente diferente dos habituais, ou por voz ou sistema operacional menos difundido.

Desta forma o sítio elaborado pelo projeto Floripacessível.com contou com uma interface acessível, projetada em linguagem XHTML e diagramação via folhas de estilo, ou CSS. As cores estabelecidas foram resultados de pesquisas prévias realizadas junto à ACIC com usuários baixa visão e gráficos coloridos transmitidos pelo monitor. O melhor contraste evidenciado foi o de fudo preto com letras amarelas, pois se mostrou o menos "cansativo" segundo os usuários entrevistados (LABTATE, 2007). Alguns recursos de acessibilidade foram utilizados na página como os botões de "aumentar e diminuir letras" que melhoram a acessibilidade dos usuários com baixa visão. Para os usuários cegos o recurso mais evidente é o botão "ir direto para o conteúdo" que faz com que o sintetizador de voz não precise ler toda a página para que o usuário alcance a informação desejada, assim ele pode ir diretamente para o conteúdo que lhe interessa, sem muitos cliques. 
Figura 4 - Interface do sítio Floripacessível.com

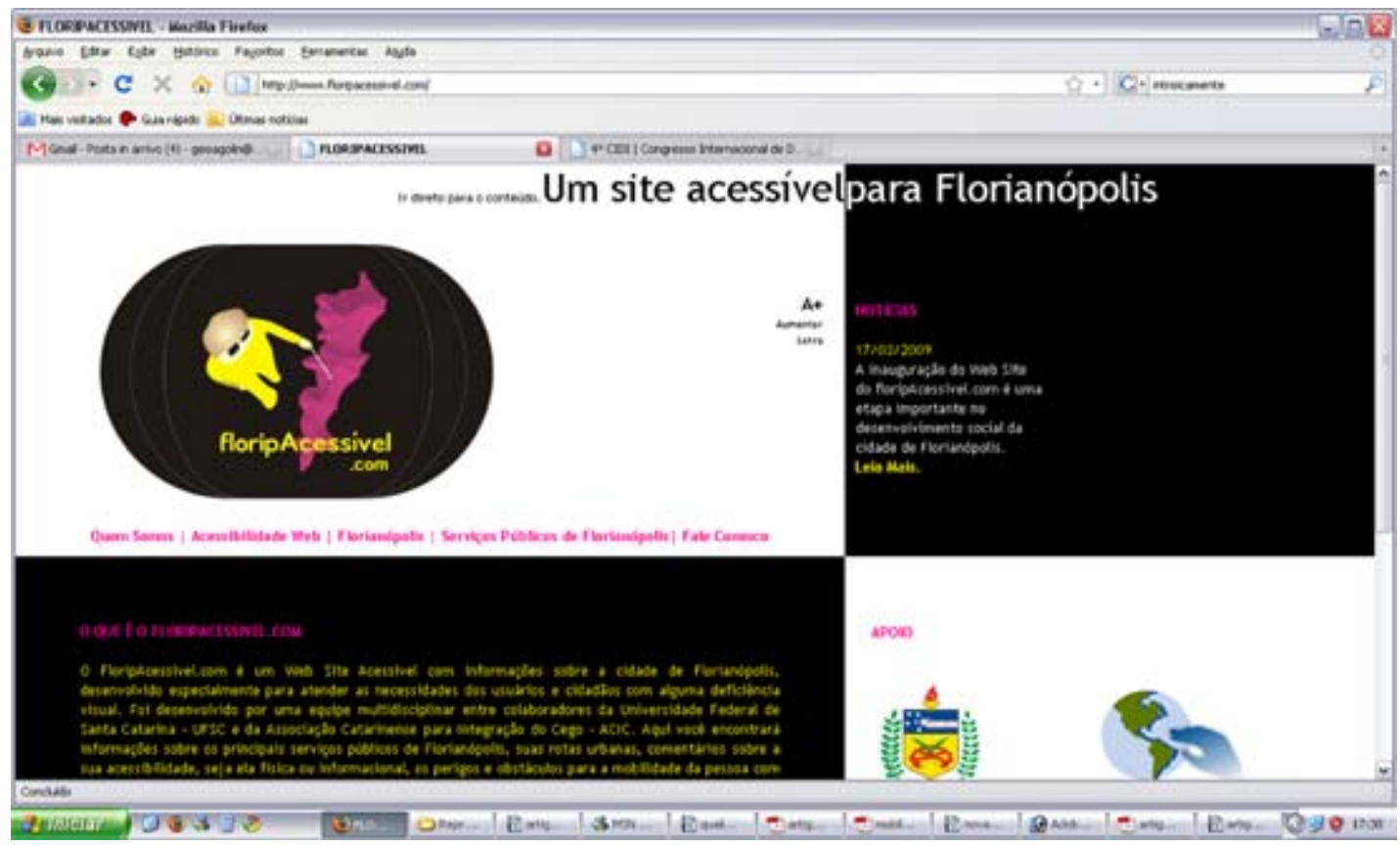

A função do sítio é informar cidadãos florianopolitanos com deficiência visual mas também turistas, que vindo à cidade, possam fazer melhor uso dos espaços urbanos. A disponibilização das informações no sítio acontece de três formas. O usuário encontra diversos serviços públicos divididos por categorias: saúde, educação, lazer, circulação e mobilidade e comércio. Escolhendo a categoria o usuário se depara com a lista de serviços públicos, escolhendo, por exemplo, a rodoviária existem três formas de perceber este serviço. A primeira forma é via texto, ou seja, o usuário pode ler ou então escutar via programa de leitura de voz instalado no computado. A segunda forma de acesso é via áudio: um arquivo de formato mp3 é disponível com a explicação do serviço público bem como a rota mais segura e acessível para se chegar a este lugar. A terceira forma de acesso à informação é via mapa tátil de rota urbana; ou seja, o usuário pode fazer download do mapa e com o auxílio de um amigo ou familiar confeccionar o seu próprio mapa tátil.

Segundo as experiências já relatadas por usuários, as três formas de acesso à informação se complementam, ou seja, o usuário pode ler ou escutar via voz a explicação de texto, diretamente na Web. Em seguida ele pode fazer download do audio mp3 e colocar no seu mp3 player, assim ao percorrer o caminho pode ouvir as explicações da rota. Já o mapa tátil de rota complementa o conhecimento espacial do usuário.

O Floripacessivel.com foi validado pelos usuários invisuais que participaram da pesquisa e também por avaliadores online como o sítio brasileiro "Dasilva", recebendo um selo de acessibilidade. Outros selos importantes também foram alcançados pela equipe como o selo de XHTML, linguagem sugerida pelo W3C, e ainda o selo comprovando o uso de CSS, ou folhas de estilo que asseguram a acessibilidade à Web.

Figura 5 - Selos validando a acessibilidade do Floripacessivel.com.

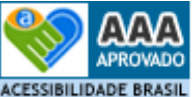

$$
\text { W3C css }
$$




\section{Infodesıgn}

\section{Conclusões}

As pesquisas envolvendo Web acessível e o estudo aprofundado sobre a temática do deficiente visual são fundamentais para compreender as novas medidas de construção de conteúdos, sejam eles urbanos ou virtuais. Entender como o deficiente visual percebe a cidade e o espaço em que vive torna o projeto urbano muito mais eficaz a todos, favorecendo não apenas uma massa homogênea de usuários, mas sim as particularidades de todos.

A Web acessível por outro lado é uma importante ferramenta que dá acesso à informação. Suas normas, quando seguidas pelos designers e projetistas, proporcionam que mais usuários estejam participando da grande aldeia global. Dar possibilidade aos deficientes visuais de conhecerem a sua cidade via Web é torná-los cidadãos.

\section{Agradecimento}

Agradecemos a toda a ACIC - Associação Catarinense para Integração do Cego, pelo forte apoio junto às pesquisas.

\section{Referências}

ACSELRAD, Henri. A duração das cidades: sustentabilidade e risco nas políticas urbanas. Rio de Janeiro: DP\&A Editora, 2001.

CREMONINI, R. S. C. A percepção do espaço físico pelo usuário: uma compreensão através de mapas mentais. Universidade Federal de Santa Catarina. Dissertação (mestrado em Engenharia de Produção). Florianópolis, 1998.

KOZEL,S.Comunicando e representando: mapas como construções socioculturais. In: A aventura cartográfica: perspectivas, pesquisas e reflexões sobre a cartografia humana. SEEMANN, Jorn. (org) Fortaleza: Expressão Gráfica, 2006.

IBGE. Censo demográfico de 2000. Disponível em http://www.sidra.ibge.gov.br - Acesso em 30/06/2007.

INSTITUTO BENJAMIN CONSTANT - IBC. Deficiência Visual. Disponível em: www.ibc.gov.br. Acesso em 28 Jul 2007.

LARAMARA. Deficiência Visual. Disponível em: www.laramara.org.br. Acesso em: 25 Jul 2007.

LERNER, Jaime. Acupuntura Urbana. Rio de Janeiro: Record, 2005.

SCARINGELLA, Roberto Salvador. A crise da mobilidade urbana em São Paulo. São Paulo: Perspec, 2001. SciELO Brasil.

W3C, World Wide Web Consortion. Disponível em: http://www.w3.org/. Acesso em 05 fev 2007.

WAI, Web Accessibility Initiative. Disponível em: http://www.w3.org/WAl/. Acesso em: 05 fev 2007.

WDG, Web Design Group. Disponível em: http://www.htmlhelp.com/. Acesso em 12 fev 2007. 


\section{Sobre os autores}

Geisa Golin, Mestranda UFSC, docente do Grupo UNIASSELVI - Famesul. É graduada em Design pela Universidade Federal de Santa Catarina (2005). Especialista em Outdoor Design pelo Politecnico di Milano - Itália (2008). Mestranda do Programa de Pós-Graduação em Engenharia Civil - Cadastro Técnico e Gestão Territorial, Universidade Federal de Santa Catarina, em adamento. Foco de Pesquisa em Design Universal, Acessibilidade Web para Deficientes Visuais e Baixa Visão.

<geisagolin@gmail.com>

Ruth Emilia Nogueira, Doutora, UFSC. Possui graduação em Engenharia Cartográfica pela Universidade Federal do Paraná (1983), mestrado em Geografia pela Universidade Federal de Santa Catarina (1991) e doutorado em Engenharia Florestal pela Universidade Federal do Paraná (2000). Atualmente é professor associado 1 da Universidade Federal de Santa Catarina. Tem experiência na área de Geociências, com ênfase em Cartografia, atuando principalmente nos seguintes temas: Cartografia, Cartografia Tátil e Escolar, Sensoriamento Remoto e SIG aplicados aos estudos ambientais.

<ruthenogueira@gmail.com>

Gabriela Custódio Alexandre, acadêmica do Curso de Geografia da Universidade Federal de Santa Catarina. É bolsista do LABTATE - Laboratório de Cartografia Tátil e Escolar. Desenvolve atualmente seu Trabalho de Conclusão de Curso em Cartografia Tátil sob orientação da Professora Ruth Emilia Nogueira.

Josiane Márcia Cabral, especialista. É graduada em Design pela Universidade Federal de Santa Catarina (2005) e possui MBA em Marketing pela Fundação Getúlio Vargas - FGV (2008). Atualmente atua como Coordenadora do Curso Superior de Tecnologia em Design Gráfico do Grupo UNIASSELVI - Famesul, ministrando disciplinas para os cursos de Design Gráfico e Design de Moda. <josi_cabral@yahoo.com> 